\title{
Beauty in the Eyes of the Akan People of Ghana: A Sociolinguistic Analysis of Alex Konadu's Song "Asianawaa"
}

\author{
Cynthia Elizabeth Osei ${ }^{1}$, Emmanuel Yaw Appiah ${ }^{1}$, Emmanuel Antwi Fordjour ${ }^{2}$ \\ ${ }^{1}$ Liberal Studies Department, Kumasi Technical University, Kumasi, Ghana \\ ${ }^{2}$ Department of Modern Languages, Kwame Nkrumah University Science and Technology, Kumasi, Ghana
}

Email address:

cynthiaosei1305@gmail.com (C. E. Osei),2016appiah@gmail.com (E. Y. Appiah), eafordjour@gmail.com (E. A. Fordjour)

To cite this article:

Cynthia Elizabeth Osei, Emmanuel Yaw Appiah, Emmanuel Antwi Fordjour. Beauty in the Eyes of the Akan People of Ghana: A

Sociolinguistic Analysis of Alex Konadu's Song “Asianawaa”. International Journal of Literature and Arts. Vol. 9, No. 4, 2021, pp. 155-160. doi: $10.11648 /$ j.ijla.20210904.12

Received: June 18, 2021; Accepted: July 2, 2021; Published: July 13, 2021

\begin{abstract}
Beauty is a universal concept and has many facets. But the standards of measuring beauty are arbitrary and differ from one culture to another. The variations in the ideals of beauty show what is expected of women in any society. In the Western world, the standards of beauty do not extend beyond the physical appearance of a woman. In the African cultural setting, particularly in the Akan culture, the standards of beauty are not limited to only the physical appearance of the woman. How language is used in exploring the standard of beauty in the Akan has received a little attention. This paper seeks to focus on the use of language used in expressing beauty in the Akan society. Using data based on the song entitled "Asianawaa", by Alex Kwabena Konadu, a well-known Ghanaian musician, this study examines the Akan concept of beauty as reflected in the use of language. Konadu captures the notion of beauty, through the female physical features, non-physical features and the social capital of beauty. The metaphor, allusion and symbolism are the main language tools that help to conceptualise the concept of beauty in this Akan song. The findings reveal that Konadu's lyrics highlight the metaphorical concept of beauty with its connotations. It draws conclusion that Konadu's idea of beauty is demonstrated in understanding the relationship between the language and the socio-cultural experiences of the Akan of Ghana.
\end{abstract}

Keywords: Beauty, Akan, Culture, Female Curvature

\section{Introduction}

The concept of beauty is very broad. Beautiful is what we like, what is fascinating, interesting, great, maybe funny or inspiring to us [10]. In many ways, beautiful things and people create pleasure. This pleasure can to some extent be intense and may be experienced in many different ways. According to Donne, pleasure is the main ingredient of aesthetic experience and the everyday usage of the word beautiful based on the human experience is the pleasurable feeling that is found in the perception of each individual.

The standards of beauty are arbitrary and they vary greatly from one culture to another. Such variations in the ideals of beauty often depict the roles women are expected to play in society.

In the Western world, the dominant standard of female beauty may have been changing over time, but for a long period of time, symmetrical, toned, white thin women have been portrayed as the ideal. In this wise, the ideal beauty is white, super thin blonde with straight hair [21]. Such aesthetic beauty is a reflection of the white cultural values and European colonial past. In recent times, however, there has been an increased visibility for diverse body types. This indicates there is not one kind of body that is beautiful. In very specific terms, according to Hill [14], physical features such as skin colour, hair texture, eye colour, nose and lip shape become the symbols of female's beauty, social status and distinction. To a great extent, physical appearance becomes a very important feature for women. White beauty ideals exclude the phenotypic features of black women.

However, Jackson-Lowman [16] observes that within the African cultural setting, there is more to beauty than the 
physical appearance of a woman. Beauty is defined in nontangible ways. There is non-adherence to the mainstream beauty standards which are represented through white models. Swain affirms that beauty is a way of being rather than a physical trait or one's appearance. She advances that character is an important element in the evaluation of beauty and, this is particularly so because nature with its phenomenal diversity offers a model of range and variety that any definition of beauty may accept. This position is in line with the African worldview which places emphasis on the diunital approach in analysing beauty. A single monolithic standard in assessing beauty is unsustainable.

In the Akan language, the word ahofe means the state of being very beautiful or handsome and the qualities of such beauty or handsomeness attract the attention and when the word is mentioned it is mainly about the physical appearance of the person. This word aho fe has been used in the text under study and according to Diabah and Appiah Amfo [9] there are Akan proverbs that project that women pay particular attention to their physical appearance. However the characteristics that define beauty have rarely been the focus of attention in a language study.

In this work, beauty will be defined as any reference to physical or non-physical characteristics that offer satisfaction to women. This will cover the physical aspects of beauty such as skin colour, eyes, hips, hair, nose, dressing, and dental formation, while non- physical aspects such references to general comportment will also be considered.

The aim of this paper is to demonstrate how language is used to describe the female beauty in a Ghanaian song. It will show whether the definition of beauty in the African context or western standards or both are used as the main reference of women's beauty in a Ghanaian highlife song.

\section{Concept of Song: Origin and Debates on Ghanaian Songs}

The study of songs, according to Turpin and Stebbins (2010) often connects with many fields of linguistic inquiry because songs are form-meaning units that can be found in any complete language description. Songs are highly structured art forms that have the tendency to render complex association of meaning beyond every day spoken language. Songs are of importance because they most often possess distinct readings from that which would be assigned to them on the fact of their straightforward compositional semantic principles. Again songs convey more meanings and significances than an ordinary speech utterance and in this respect, songs share some characteristics as poetry. Furthermore, songs are deeply embedded and have artefactlike status of the text. This feature is also common with some linguistic forms such as poetry, proverbs and religious sermons [22]. These language arts feature prominently in Ghanaian songs. Within the Ghanaian context, songs play vital roles in the culture. Annin [4] posits the correlation between the verbal content of the songs and other areas of culture. For Annin, Ghanaian songs portray nearly every occasion or circumstance, including "ceremonial and work songs, occupational songs, contest and victory songs" (41). Songs such as Highlife are the traditional roots of Ghanaian songs with Akan rhythms and melodies that encompass a variety of artistic expressions such as story- telling, music, singing and drumming. Highlife plays a role as an agent of change and agent of affirmation for traditional values. Highlife changed this role by reflecting the realities of current socio-cultural experiences discussed in the scholarly works below.

\section{Literature Review}

The major theoretical framework for this study is the intersection of language and culture, but the defining concept that will be applied is the notion of context. According to Godwin and Duranti [13] it is very difficult to put a stamp on the right definition of context. However they argue that culture constitutes the background from which language, which can be verbal or non- verbal, derives its interpretation. Godwin acknowledges that what constitutes background and focus undergoes a change as the interaction moves on. Context becomes a 'frame' that is around the phenomenon or event that is under the examination and at the same time offers sources for its appropriate interpretation [13].

So in the present study, there is the overarching dimension of context at play. This is the cultural context which revolves around our understanding of social norms and the behavioural expectations and practices that govern beauty as physical appearances or non-physical traits. This cultural component is defined and is referenced in the linguistic meaning conveyed in expressing beauty. This is so because according to Agyekum [2], an effective coordination between language and culture provides an understanding of politics, concepts, perceptions, worldviews and people's intellect, psychological behaviour and the sociocultural world. Any path to understanding the cultural notion of beauty and its dimensions in Konadu's song Asianawaa is not distinct from the language and culture within the specific context of the Akan sociocultural norms and practices.

This work draws on the influential previous studies [2] and [3] of the relationship between language and context in Konadu's songs. Agyekum [2] is very useful for this work, particularly because it analyzes the Akan socio-cultural perspectives as captured in Konadu's Asianawaa while Agyekum [3] delves into the theme, sociocultural implication and the language and style of another song of Konadu. These works are a revealing setting for the methodological and analytical paths for the present work and add on to the study of Konadu's songs in particular, and language and culture in general.

Within the realm of studies of text and context in Ghanaian songs, Acquah [1] offers significant signposts in methodology, theory and analysis for the present work. The work on tropes on Asafo songs in Fanti but translated into English, and analysed for tropes makes an impact on the 
present work with similar language features. However, the differences in the function and themes of the songs are less significant particularly in bringing out the objectives of the present study.

Beyond Ghanaian songs, Nurcitrawati et al [18] explores the use of figurative language in the lyrics of Disney songs, seeking to find the types and functions of figurative language and the implicit meanings. Apart from these objectives, their qualitative description approach is similar to this work. They provide a guide to this work. However, Disney's song lyrics are in English which lends itself to a straightforward analysis while this work is in Twi.

Analysing the use of figurative expression in ancient Egyptian love songs, Hsu [15] underscores the significant relationship between language, culture and context. Hsu's work offers important grounds for studying a concept such as love in a song, as this work delves into language of beauty through the cultural lens. Hsu's work suffers from an inadequate description of methodology that the present work can depend on.

To understand language and culture, it is very significant to focus attention on other aspects of the Akan culture such as the description of beauty. This study therefore provides an opportunity to integrate insights from the study of aspects of language, norms and values of the Akan, and to further our understanding of language and culture.

\section{Methodology}

The data for the study is a song by Alex Kwaku Konadu called "Asianawaa". The complete play of the song was culled from the You-tube and transferred onto a mobile phone. The duration of the song is eight minutes and fourteen seconds. The main reason for selecting "Asianawaa" was that, in a large measure, the song references many aspects of feminine beauty, though there are other themes which are not relevant for the present study.

The song was transcribed from the audio on the mobile phone and translated from Akan (Twi) into English. The song consists of five stanzas and each stanza describes the present predicament of the named persons, Abena and Kwabena, after they have squandered their opportunities. The first describes the predicament of Abena as an orphan while the second stanza tells of Asianawaa's refusal to eat. The third stanza recounts opportunities of Abena in her prime and the consequences that come after losing the opportunities. The fourth predicament shifts to Odisika Abrantie and the after effects of his extravagance and profligacy. The fifth stanza deals with the regrets of Abena's refusal to take a husband and her failure give birth to her children.

After thoroughly reading the song, we identified and categorised the sentences which mentioned aspects of beauty relating to a woman. We cross-checked the aspects of beauty with two other scholars (They are lecturers at the Kumasi Technical Institute and Kwame Nkrumah University of Science and Technology). The physical features, nonphysical features and the social capital of beauty were highlighted in this study.

Alex Kwabena Konadu was a skilled highlife composer in Ghana. His songs, dating from 1975 to 2011, cover many aspects of the sociocultural life of the Ghanaian. The major themes of Konadu's composition included marriage, love, social practice, religious beliefs, poverty, moral values, death, disease, Akan myths and legends and politics, oppression and discrimination.

\section{Analysis of Konadu's “Asianawaa”}

The first part of the discussion offers a descriptive analysis of the physical features, non-physical and benefits of beauty that are identified and place them within their sociocultural context, while highlighting the linguistic features that bring about their realization. In these, we demonstrate that the language used constitute a system of thought but not mere description of reality in the Akan society.

\subsection{Physical Features}

Appearance is a key function of the creation of very broad view of woman [12] and the attributes of external beauty are directly linked to the notion of Akan and other cultures.

\subsubsection{Skin Colour Satisfaction}

Konadu's song references the skin satisfaction in two ways. According to Draelos [11] and Phelon [19] skin colour satisfaction has been the obsession for human beings in all cultures and the pursuit for skin satisfaction is not the preserve of only Eurocentric adherents.

Na me kokoo, me, nua, tese mmorngo

My fair complexion, my sibling, is like cycad

This draws our attention to the complexion of Asianawaa. Here, kokoo refers to her fair complex while mmorongo is a reference to the cyacd. The description of her complexion is akin to the cycad, an ornamental tree which is mostly found in the tropics. In this nature of this ornamental tree, the fruits grow to adorn its tree and brighten the environment. Her skin complexion and how brightly it is makes the symbol of the mmor ongo a reality. So obvious is the fair complexion of Asianawaa which brightens to provide the skin colour satisfaction that arises from natural endowment. This description hinges on Konadu's creative knowledge of Akan natural environment and he exploits this symbolism as a means of conveying the truth of Asianawaa's complexion as natural and bright.

The second reference to the skin colour satisfaction however arises from a different phenomenon.

Mes ore an opa nso a, medware mesesra fefefee

Me honam sokyee me nua tese asikyire

When 1 woke up in the morning, 1 bathed and polished myself very nicely

My skin very succulent, my sister, like sugar

Here Asianawaa's bathing and cleanliness of her body becomes an obsession since she does that every morning after waking up from bed. But the cosmetics she applies to make her body succulent and attractive are unnatural. Here Konadu uses simile drawn from Akan belief that succulence 
is to be cherished. This succulence of the skin is attained after bathing and applying body cream, a reference to cosmetics, to her skin. The sense of naturalness is absent when the simile of tenderness of sugar and the skin after bath and application of cosmetics is brought into a sharp focus. The language here evokes the sense of artificiality and unnaturalness of beauty. This language directs concerns about the sustainability of her attractiveness after the failure of the cosmetics.

\subsubsection{Leg}

Konadu relies on another physical appearance of Asianawaa to draw beauty.

M'anantu a mekura ene anwenee bodom mmowuo

My calves 1 have and expensive beads

This part relates to her leg as adorned with beads. The wearing of beads is popularly held to be significant in creating physical beauty anatomically among Ghanaians. The beads, according to Asare [5], are considered not only as a form of jewellery that denotes sexuality on the body but more importantly, the beads constitute objects of adornment of the knee, ankles, neck, arms, elbows and wrists that accentuate the female curvature and present the woman as desirable to watch. The beads, anwenee bodom mm owuo form her calves into an extraordinary shape considered as beautiful in the Ghanaian sense of judgement and makes a great impression on men and many others who look at her. According to Akan oral tradition, this type of bead, bodom, which is either multi-coloured with yellowish background designs or with long stripes of dust, was exchanged for gold in the fifteen century. So this bead marks Asianawaa out not only as a person who is not only beautiful but expensive, of higher status-like that of a queen. This accords the language with some allusive force.

\subsubsection{Gait}

Another way beauty is crafted in the song is through Asianawaa's gait. Benamou [6] asserts that in many cultures, the feet and the manner of walking can reveal the ideal feminine beauty, and the manner of walking can offer the protection for the feet.

Na metea fam nso a, mentia no kese

When 1 step on the ground, l don't step on it hard

The description of her manner of walking, a charming female pace, is taken from the Akan practice of how the great kings and queens should walk. According to Gasanova and Gasanova [12] a charming female pace is stately, slowly and proudly and in alluding to Asianawaa's gentle steps, Asianawaa is cast as a great queen who walks with grace that exudes beauty. She takes her time to walk so as not to stumble. The language being manipulated by means of allusion equates the value of her beauty to a queen, a highly respected leader in an African society.

\subsubsection{Neck}

The neck constitutes one of the physical traits that can reveal the standard female beauty and this is exploited in the Konadu's song "Asianawaa" by relying on the Akan kente weaving experience.

\section{Mekon nnua tese serekye ahoma}

The lines around my neck are like the silk thread

Here the wrinkles around Asianawaa's neck are compared to the silk thread which is the most exotic and expensive thread used in weaving the kente cloth. Possessing and wearing cloth made of silk thread such as kente affords the person with a prestige that is unparalleled. The metaphor of the silk thread as lines around Asianawaa's neck is drawn from Akan sociocultural practice. There are many threads for making fabric and so are there the varieties of the quality available for producing fabric. Of the varieties, silk thread is reputed to be the most exotic and expensive. Because of the high cost of the silk thread and the highest quality of kente that the silk thread produces, it is rarely used in making kente cloths for the less privileged except those kente cloths being made for kings and queens and for the very rich Akan folks. The lines around the neck of Asianawaa are not as the result of age, but are marks which enhance her physical appearance and make her a beautiful woman. The lines around her neck which are uncommon, constitute a metaphor of the rare natural endowments of her beauty.

\subsubsection{Dental Formation}

Sherrow [20] and Nalbandian and Milar [17] underscore the importance of facial attractiveness based on the colour and alignment of one's teeth. This is not an exclusive Eurocentric worldview. In this Akan song, Konadu makes use of Asianawaa's dental formation to draw her beauty.

Mesemu gyere, mesere baako a eye odo

Look, my gap in my teeth, when 1 smile once reveals love

This specifically portrays some elements of her beauty. $\mathrm{He}$ refers to the interdental or midline dental space - the gap between the two upper front teeth of Asianawaa and her smile. The harmony between the midline dental space and her smile is extraordinarily attractive and protrudes its expression of emotional contagion. What Asianawaa's smile and her teeth gap do is to raise the potency of the love around her and towards her. The language of metaphor written as the eroticism in her teeth gap and her smile becomes attractively powerful to draw men toward her.

\subsubsection{Eyes}

Konadu crafts the attractiveness of Asianawaa by making reference to her eyes.

\section{M'animmayi nso, tese nhwiren}

My eyes are also like flowers

The attractiveness of the eyes as a physical trait is not limited to the Akan culture. Chua [8] affirms that the influences of both Japanese and western culture and fashion propel women to undertake surgery to get eyes that are appealing. Here the expression invokes the image of flower which is brightly coloured and is appealing to attract attention. Flowers that are bright in colour are specially meant to attract birds, bees and other insects to reproduce. The eyes become the function of adornment which does not only beautify her but makes her very attractive to men. Here Konadu places Asianawaa's attractiveness in the context of nature and mobilizes the Akan notion to that effect. 


\subsection{Non-Physical Features}

According to Swain [21] among African and some descent of Africans, the non-physical description of beauty makes it potentially open to all people. With this, beauty is seen in terms of how one expresses inner or inward feelings on the outer body. The attributes of this form of beauty are described as intangible, persona or character that one has. They comprise strength, pride, intelligence, confidence etc.

In "Asianawaa", there is little to be found of what can be described as non-physical beauty.

\subsection{Beauty as Symbolic Capital}

Beauty as symbolic capital [7] is evidenced in "Asianawaa". Bourdieu explains symbolic capital as social capital which results in greater social opportunities. In this context, ideals of beauty for an Akan woman should better her chances for procuring a potential husband. Beauty becomes a means to the end of getting a husband.

Na m'ahofe nso nti no, na anka meregye nkurofoo kununom

Because of my beauty, 1 was snatching others' husbands

This literal meaning of this statement is ironic. Here Asianawaa's beauty affords her the social capital, but it is devastating and unproductive. This is because her beauty only enables her to snatch the husbands of other women. It does not empower her to secure her own husband. Indeed, in the Akan culture, a woman who snatches women's husbands has a little reputation.

\section{Conclusion}

This paper investigated the role of cultural context in understanding how beauty is expressed in a song. It looked at beauty in terms of physical features, non-physical features and beauty as a social capital.

It was discovered that physical features which are mostly based on the western and African worldviews are described as the main features of beauty but the language used in describing these features are drawn from the Akan cultural context. Metaphor, allusions, simile and irony are used as the main tools of language to capture the beauty of a woman.

There are references to natural physical features that enhance beauty and artificial means of boosting the beauty of a woman. Contrary to the notion that Africans espouse the non-physical features as the main attributes of beauty, this study showed that there is no beauty attributable to a nonphysical feature. The social capital of beauty, found in the study, was more devastating than liberating.

The study provides an understanding of the relationship between language, and culture. In particular the study has highlighted the types of meaning of beauty and the ways in which the meanings of beauty are expressed. It demonstrates that culturally ascribed meaning can be gleaned through interpretation to elucidate broader meanings. A future examination of other themes can be studied to get full import of Konadu's songs.

\section{References}

[1] Acquah, L. J. (2002). A repertoire of Tropes: A study of Fante Akan Asafo songs texts from the Cape Coast area of Central Region of Ghana. Unpublished M. Phil Thesis, University of Cape Coast.

[2] Agyekum, K. (2016). The sociocultural concept of ohia, poverty in Akan: Konadu's songcnnemekjnamaba. South African Journal of Languages, 36: 2, 163-171.

[3] Agyekum, K. (2005). An Akan oral artist: The use of proverbs in the lyrics ofKwabenaKonadu. Research Review NS 21 (1): $1-17$.

[4] Annin, F. (2014). Poetry of Ghanaian Hip-Life Music: Reflections on the Thematology of Selected Hip-Life Songs. IOSR Journal of Humanities and Social Science. 19 (1), 41-48.

[5] Asare, S. (2014). Erotic expressions in Adowa dance of the Asante: The stimulating gestures, costuming and dynamic drumming. Journal of Music and Dance, 4 (1): 1-9.

[6] Benamou, P. H. (2006). Erotic and sadomasochistic foot and shoe. Behavioural Study, 22: 43-64.

[7] Bourdieu, P. (1990). The Logic of Practice. Stanford: Stanford University Press.

[8] Chua, K. C. (1982). Double Eyelid surgery in Singapore. Aesthetic Plastic Surgery, 6: 221-223.

[9] Diabah, G \&Amfo, N. A. A. (2014). Caring supporters and or daring usurpers? A representation of women in Akan proverbs. Discourse \& Society, doi. 10: $1177 \mathrm{http} /$ das.sagepub.com

[10] Donne, D. V. (2010). How can we define beauty? A psychological answer to a philosophical question. Proceedings of the European Society for Aesthetics, 2: 88-99.

[11] Draelos, Z. D. (2002). Self-tanning lotions: Are they a healthy way to achieve a tan? American Journal of Clinical Dermatology (5): 317-318.

[12] Gasanova, M., Magomedova, P. \&Gasanova, S. (2016). Linguoculturological analysis of woman's image in proverbs and sayings of the Dagestan languages. International Journal of Environment and Science Education, 11 (18): 1186911887.

[13] Godwin, C. \& Duranti, A. (1992). Rethinking context: an introduction. A. Duranti \& C. Godwin (Eds.). Rethinking context: Language as an Interactive Phenomenon, Cambridge: Cambridge University Press. (1-43).

[14] Hill, M. E. 2002). Skin color and the Perception of attractiveness among African Americans: Does gender make a difference? Social Pyschology Quarterly, 65 (1): 77-91.

[15] Hsu, S. W. (2014). The images of love: The use of figurative expressions in ancient Egyptian love song. Orientalia 83 (4): 407-416.

[16] Jackson-Lowman, H. (2013). An analysis of the impact of Eurocentric concepts of beauty on the lives of African American women. In H. Jackson-Lowman (ed). African American women: Living at the crossroads of race, gender, class and culture (pp, 155-172). San Diego, CA: Cognella Academic Publishing. 
[17] Nalbandian, S. \& Millar, B. J. (2009). The effects of veneers on cosmetic improvement. British Dental Journal, 207, E3: 15 .

[18] Nucrcitrawati, V., Kareviati, E. \&Atmawidjaja, N. S. (2019) Figurative language analysis in Disney songs. Project. 2 (4): 494-500.

[19] Phelan, S. T. (2002). Fads and Fashions: The price women pay. Elsevier Science, 138-143.
[20] Sherrow, V. (2001). For appearance sake: The Historical Encyclopaedia of good looks, beauty and grooming. Westport: Oryx Press.

[21] Swain, F. O. (2012). Negotiating beauty ideals: Perceptions of beauty among female university students. Unpublished M. A. Thesis. Georgia State University.

[22] Turpin, M. \& Stebbins, T. (2010). The language of song: Some recent approaches in description and analysis. Australian Journal of Linguistics, 30 (1) 1-17. 